\title{
ETFE for Innovative Building Envelopes, Research Activities at HFT Stuttgart
}

\author{
Liebhart H.*, Cremers J. ${ }^{\dagger}$ \\ ${ }^{*}$ Hochschule für Technik Stuttgart (HFT) \\ Schellingstr. 24, 70174 Stuttgart, Germany \\ e-mail: heiko.liebhart@hft-stuttgart.de,web page: http://www.hft-stuttgart.de \\ ${ }^{\dagger}$ Hochschule für Technik Stuttgart (HFT) \\ Schellingstr. 24, 70174 Stuttgart, Germany \\ e-mail: jan.cremers@hft-stuttgart.de,web page: http://www.hft-stuttgart.de
}

\begin{abstract}
The use of tensile materials in general, and fluoro polymer foils like ETFE in particular, for the building envelope bears great potential in terms of artistic freedom as well as building physics aspects like natural daylight provision due to its material properties like weight, durability, transparency and the self-cleaning surface.

In the corresponding article we give an overview on the recent research activities and innovations in the field of ETFE building envelopes. We discuss the multifaceted aspects of the topic based on investigations from recent, ongoing and future research projects conducted at HFT Stuttgart.

We elaborate on the peculiarities of the proper numerical modelling of the thermophysical phenomena within ETFE membranes and discuss novel surface treatments to improve the emissivity properties of ETFE (low-e). We give an overview of innovative cushion configurations with optoelectronic elements like organic photovoltaics for energy harvesting and electrochromic elements for dynamic shading (g-value). Finally we include some considerations on the sustainability of ETFE structures for the building envelope with regard to the impact on the overall energy demand of buildings and general life cycle assessment aspects of the polymer material itself, it's treatments and modifications, as well as the supporting structure.
\end{abstract}

Results in terms of numerical simulations on the impact of the applied technologies on the overall energy demand of exemplary buildings will be presented alongside some actual physical configurations in the form of technological demonstrators.

In concluding remarks we will elaborate briefly on the prospects of upcoming research projects concerning membrane structures at HFT Stuttgart.

\section{REFERENCES}

[1] Liebhart, H.; Cremers, J.; Mirbach, D.; Marx, H., Wärmetransport und andere bauphysikalische Aspekte im Membranbau, Stahlbau 89(8), 672-683, DOI: 10.1002/stab.202000050, (2020).

[2] Cremers, J.; Marx, H., Assessment of building Physical Aspects of a New Angular Selective 3D Prototype Foil (ETFE), Proceedings TensiNet Symposium 2019, Mailand, p. 592-601, DOI: 10.30448/ts2019.3245.01, (2019).

[3] Cremers, J.; Liebhart, H.; Mirbach, D., Potential Energy Saving via Dynamic Shading with Electrochromic Elements in ETFE Windows, BauSIM2020, DOI 10.3217/978-3-85125-786-1 (2020) 